\title{
Research on Economic Dynamic Efficiency of China - Based on AMSZ Model \\ Zihao Chen
}

School of Economics, Shanghai University, Shanghai, China

18621568293@163.com

\section{Keyword: China's Economy; Dynamic Efficiency; AMSZ Model; Net income}

\begin{abstract}
In this paper, the dynamic efficiency of Chinese economy is studied by using AMSZ model. The result shows that the economic dynamic efficiency of China was significant volatility before 2008, but there was no significant dynamic inefficiency. From 2005 to 2007, the net capital gains were high, so we cannot say that there is excessive investment in China. However, after the financial crisis in 2008, China's economy has entered a new normalization, and the economic structure is facing a transition. Even so, only slight dynamic inefficiency can be seen from the indicators of NI / GDP. As a developing country, the per capita capital stock of China is still low; we cannot ignore the role of investment in stimulating economic growth.
\end{abstract}

\section{Introduction}

Since the reform and opening up, China's economy has maintained rapid growth, attracted worldwide attention, while China's rapid economic growth is driving by investment. Due to the long-term implementation of capital bias development strategy, China's economic structure presents characteristics of high investment rate, high saving rate, and low consumption rate. But at the same time, we also observed that China's GDP growth slowed down from $7.7 \%$ to below $8 \%$ in 2012 , $7.7 \%, 7.3 \%$ and $6.9 \%$, respectively, indicating a new normalization of the China's economy.

In view of this, many scholars direct judgment is that China's saving rate, investment rate is too high, consumption rate is too low, many studies also focus on the reasons for high savings, how to improve China's consumption and so on. This paper argues that we cannot judge the Chinese saving rate and the investment rate from the intuitionist and simple international comparison. This judgment must have a theoretical basis and be validated on an empirical basis.

Dynamic efficiency refers to the savings rate reaches such a level, which means making the residents of the various stages of consumption to maximize the sum of the utility, that is, to achieve the level of the gold rate. This paper argues that judging whether an economy's savings rate and investment rate are too high or not must be tested from the point of view of dynamic efficiency and the maximization of the utility of the residents.

This paper wants to explore the main issue that whether China's economy is dynamic efficient or not based on AMSZ model.

\section{Literature Review}

Foreign scholars have noted the issue of excessive capital accumulation in the economy and the first to start on the economic dynamic rate of theoretical and empirical research. These studies are mainly based on the neoclassical economic growth model. First, based on the Solow model, Phelps proposed the golden rule of capital, which is the optimal capital stock required for the economy to achieve the consumption maximization in the balanced growth path. According to this theory, by examining whether the capital accumulation in the economy reaches the golden law we can judge the dynamic efficiency of economic (Phelps, 1961) [1]. But the Solow model has its shortcomings, the golden law can only guarantee the level of human consumption to achieve maximum, but cannot achieve maximum efficiency of each person's own. The subsequent Ramsey-Cass-Koopmans model overcomes the deficiencies of the Solow model and makes the endogeneity of the deposit, in which the economy converges to a lower level than the capital stock of the Golden Rule, which is 
modified Golden rule of law. But this model also has the disadvantage that the model assumes "permanent existence and a fixed number of households," a strong hypothesis that does not help to test the dynamic efficiency of the real economy. Diamond (1965) [2] extended the intergenerational overlap model to show that the capital stock accumulated by the decentralized economy in reality may be greater than the golden law level, suggesting that there may be a loss of efficiency in a free competitive economy. In 1989, Abel et al. introduced uncertainty into the Diamond (1965) generation overlap model and proposed a new criterion for judging whether the economy is dynamic-AMSZ criteria. Abel et al. (1989) [3] pointed out that the traditional method of evaluating the dynamic efficiency is mainly by comparing the growth rate with the rate of return on assets, but in an uncertain environment there is neither a clear indicator of economic growth nor a single of the yield indicators. So they introduced the uncertainty to the model, namely AMSZ criteria. The AMSZ criterion is simply to measure the net outflow or net inflow of an economic product from the firm to the individual investor. If the product from the enterprise to the individual is a net outflow, then the economic operation is dynamic efficient; on the other hand, if the product from the enterprise to the individual is a net inflow, then the economic operation is dynamic inefficient.

In empirical testing, Feldstein and Summers (1997) [4] compared the marginal returns of US capital and economic growth rate of the size of the relationship between the measured US marginal returns of capital is about $10 \%$ higher than the same period of economic growth , The US real economy is in a dynamic and effective state. Ibbotson (1987) [5] and Cohen (1995) [6] used 19261986 and 1980-1994 two periods of US economic data, according to the economic capital stock and the relationship between the level of gold law, for different benchmark interest rates US Treasury bond yields of only $0.3 \%$, significantly smaller than the same period the average economic growth rate, the two studies have concluded that the US economy is dynamic invalid. Hahn (1995) [7] estimated the optimal savings rate in Korea based on the revised golden rule, and the savings rate is lower than that of the optimal savings, taking into account factors such as technological progress, capital adjustment costs, human capital accumulation and equipment investment Rate, indicating that South Korea savings too little, the economy is not in the long-term optimal growth path.

Compared with foreign scholars, Chinese scholars have been studying the dynamic efficiency of economy in recent years. However, in recent decades, with the continuous increase of investment level in China, scholars have begun to pay attention to whether China's economic capital accumulation is excessive. In the literature on the dynamic efficiency of China's economy, we can see that there are three main methods to test the dynamic efficiency of the economy. We have summarized this:

Compare the Capital Stock with the Level of the Golden Rule. This method is the Phelps (1966) determined the Pareto optimal economic growth with the equilibrium level of growth in capital stock based on the Solow model to. Under the standard, when the capital accumulation exceeds the level of the golden rule is dynamic inefficient. In fact, it is also possible to examine the dynamic efficiency of the economy by comparing the savings rate with the real saving rate under the Golden Rule. In this regard, scholars such as Zhigang Yuan and Zheng Song(2000) [8] first did research on the golden rule and the optimal saving rate. They found the savings rate cannot be effectively transformed into investment, and thus the individual optimal savings rate is likely to be higher than the level required by the Golden Law, lower savings rate can improve China's dynamic economic efficiency. On the basis of analyzing and summarizing previous scholars, Weili Huang and Guangjun Sui (2007) [9] estimated the optimal savings rate rule consistent with the revised golden rule by using the method of numerical simulation. After comparing with the actual saving rate from 1978 to 2003, China's actual savings rate is $38 \%$ on average, lower than the optimal savings rate of $40.3 \%$ of the benchmark value, in this sample period there is no excessive savings, the economy is dynamic and effective, but after the 1990, The actual saving rate slightly exceeds the optimal savings rate, indicating a certain degree of excess capital accumulation, this period of the economy may be dynamic inefficient.

AMSZ Model. Yongdong Shi, Yingfei Qi (2002) [10] used the AMSZ model to analyze 19921998 annual data, the result shows that China's economy is dynamic inefficient. Two approaches to 
eliminate dynamic inefficiency are discussed: the introduction of bubbles and the establishment of a pay-as-you-go pension system. Zhigang Yuan, Zhangyong He (2003) [11] did their research based on the study from Yongdong Shi. The paper uses the AMSZ criterion to test the economic dynamic efficiency of China from 1978 to 2001. The study found that before 1992, China's economic is dynamic efficient, and after 1992 the economic is dynamic inefficient. And then they discussed the dynamic ineffective from the theoretical and practical aspects of the Chinese economy in the 20th century and finally put forward the corresponding policy recommendations to get rid of the state of dynamic inefficiency.

\section{AMSZ Model}

Since the 1960s, dynamic efficiency theory has been lack of a maneuverable approach to determine the real economy there is no excessive accumulation of capital. Until Abel (1989) proposed the AMSZ criterion by introducing uncertainty into the intergenerational overlap model, the concept of dynamic efficiency is linked to the measure in the real world.

In a deterministic economy, the generation overlap model indicates that the economy in the competitive equilibrium state, there will be excessive accumulation of capital. In general, we can judge the dynamic efficiency of an economy by comparing the marginal output of capital with the size of economic growth rate. In the abstract model, the marginal product of capital is equal to its real interest rate, but in practice, corresponding to different types of assets have a different rate of return on assets, this approach is difficult to apply.

Abel assumes that the population growth rate and the rate of technological progress are all random, generalizing the overlapping generations model and proposing net cash flow criterion.

First we assume that each person has two lifetimes and give the utility function:

$$
u\left(c_{t}^{y}\right)+E_{t} v\left(c_{t+1}^{0}\right)
$$

We denote $c_{t}^{\mathrm{y}}$ the consumption of young people in period $t$, and denote $c_{t+1}^{0}$ the consumption of the elderly in period $t+1$, indicating $E^{t}$ the conditional expectation of the information available under period $t$.

At $t$ period there are $\mathrm{N}_{\mathrm{t}}$ individuals born, providing $\mathrm{N}_{\mathrm{t}}$ units of labor. Young people consume part of their labor remuneration, and the remaining savings, for old age consumption. Savings can be used to invest in the capital market, and in old age is to be held by the sale of assets, consumption-related investment income. Therefore, the individual budget constraints are as follows:

$$
\begin{aligned}
& c_{t}=w_{t}-V_{t} s_{t} \\
& c_{t+1}^{0}=\left(D_{t+1}+V_{t+1}\right) s_{t}
\end{aligned}
$$

We let $w_{t}$ represents the wage rate, $s_{t}$ represents the share of personal assets in the total market $V_{t}$, andD $D_{t+1}$ represents the total dividend. We let $R_{t+1}$ represent the total dividend from $t$ to $\mathrm{t}+1$, there are:

$$
R_{t+1}=\left(D_{t+1}+V_{t+1}\right) / V_{t}
$$

Consumers in order to make their own utility maximization, according to the following formula to allocate their own consumption and savings:

$$
E_{t}\left[v^{\prime}\left(c_{t+1}^{0}\right) R_{t+1} / u^{\prime}\left(c_{t}^{y}\right)\right]=1
$$

The identity of total consumption:

$$
C_{t}=N_{t} c_{t}^{y}+N_{t+1} c_{t}^{o}
$$

From the former we can obtain: 


$$
C_{t}=N_{t} w_{t}+D_{t}
$$

Let $Y_{t}$ represent the total output, then the profit for the investment, to arrive at:

$$
D_{t}=\pi_{t}-I_{t}
$$

Enterprises use capital and labor for production, assuming the use of generalized production technology, production function:

$$
Y_{t}=F\left(I_{t-1}, \ldots, I_{t-n} ; N_{t}, \theta_{t}\right)
$$

Competitive wage rates are:

$$
w_{t}=\partial F\left(I_{t-1}, \ldots, I_{t-n} ; N_{t}, \theta_{t}\right) / \partial N_{t}
$$

The total remuneration of capital is:

$$
\pi=\sum_{i=1}^{\infty} F_{t}^{i} I_{t-i}
$$

$\mathrm{F}_{\mathrm{t}}^{\mathrm{i}}$ represents the marginal output of capital $\mathrm{t}-\mathrm{i}$, Abel (1989) shows that if $\mathrm{Dt} / \mathrm{Vt}>0$, for all periods $\mathrm{t}$ and for all states and any number, then the economic is dynamic efficient, otherwise they represent dynamic inefficiencies. From the cash flow perspective, this formula shows that as long as the net cash inflow from investment is positive, then the economy is dynamic and effective.

\section{Measurement Results}

The method Abel used to the US economy dynamic efficiency of the empirical study, calculate the total income and total investment formula:

Total income $=$ national income + depreciation of capital - remuneration of workers - capital owners of labor income

Total investment $=$ investment in fixed assets + inventory investment

Abel did not make a careful distinction between the factors, but since the total returns in the United States were significantly larger than the total investment, it did not affect the conclusion.

Among them, I think the following points can be improved: (1) Impact of our government on investment is very large; the total investment in fixed assets investment and inventory investment contains the impact of government, so the total revenue should also include government influence. Second, in the income method to calculate GDP, GDP = labor remuneration + operating income + fixed assets depreciation + indirect tax - corporate subsidies, corporate subsidies can be seen as a tax return, included in the indirect tax, so minus indirect tax has been eliminated. The impact of corporate subsidies should not be repeated deducted. (2) Indirect tax is shared by the consumer and corporate, the enterprise should also assume part of the capital gains.

Total Revenue $=$ Operating Balance + Indirect Tax - Indirect tax on consumers + Depreciation of fixed assets

Total Investment $=$ Total Capital Formation

Net income $=$ gross income - total investment 


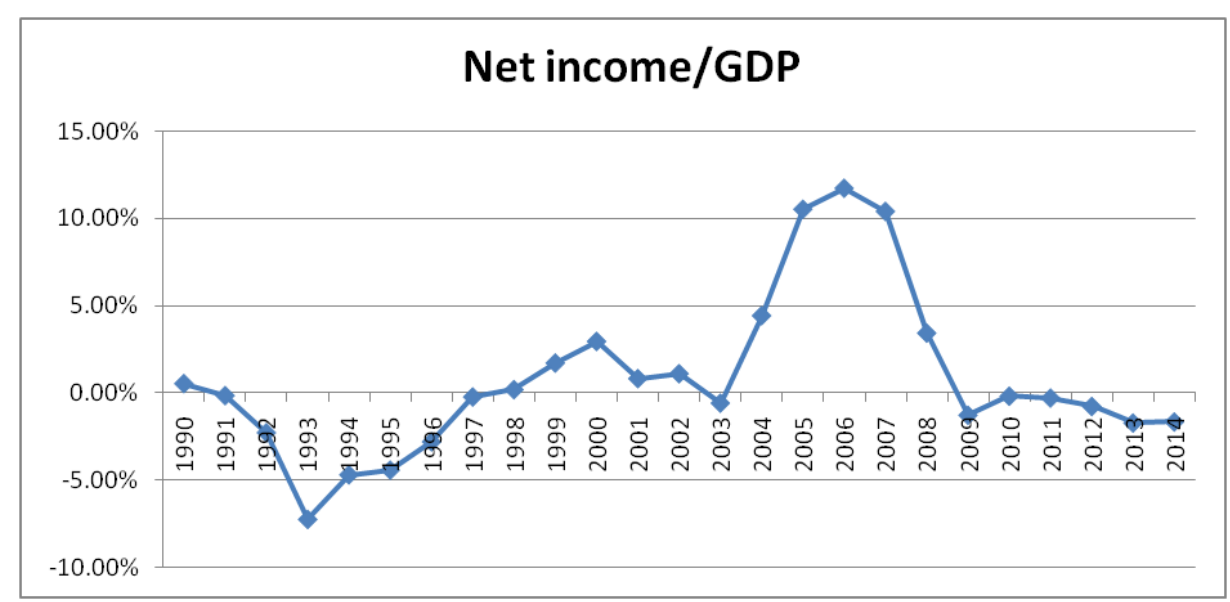

Figure 1. Net income/GDP

Table 1 Net income

\begin{tabular}{|r|r|r|r|r|}
\hline Year & Gross revenue & Total investment & Net income & Net income/GDP \\
\hline 1990 & 6655.38 & 6555.30 & 100.08 & $0.55 \%$ \\
\hline 1991 & 7862.62 & 7892.50 & -29.88 & $-0.14 \%$ \\
\hline 1992 & 10246.05 & 10833.50 & -587.45 & $-2.27 \%$ \\
\hline 1993 & 13307.67 & 15782.90 & -2475.23 & $-7.24 \%$ \\
\hline 1994 & 17789.52 & 19916.30 & -2126.78 & $-4.68 \%$ \\
\hline 1995 & 21800.11 & 24342.50 & -2542.39 & $-4.41 \%$ \\
\hline 1996 & 25641.22 & 27556.60 & -1915.38 & $-2.79 \%$ \\
\hline 1997 & 28796.66 & 28966.20 & -169.54 & $-0.22 \%$ \\
\hline 1998 & 30560.88 & 30396.60 & 164.28 & $0.20 \%$ \\
\hline 1999 & 33176.31 & 31665.60 & 1510.71 & $1.72 \%$ \\
\hline 2000 & 37405.77 & 34526.10 & 2879.67 & $2.96 \%$ \\
\hline 2001 & 41266.48 & 40378.80 & 887.68 & $0.83 \%$ \\
\hline 2002 & 46442.38 & 45129.80 & 1312.58 & $1.11 \%$ \\
\hline 2003 & 55054.97 & 55836.70 & -781.73 & $-0.58 \%$ \\
\hline 2004 & 76817.56 & 69420.50 & 7397.06 & $4.44 \%$ \\
\hline 2005 & 98368.09 & 77533.60 & 20834.49 & $10.53 \%$ \\
\hline 2006 & 116941.43 & 89823.30 & 27118.13 & $11.74 \%$ \\
\hline 2007 & 140746.79 & 112046.80 & 28699.99 & $10.41 \%$ \\
\hline 2008 & 149249.06 & 138242.80 & 11006.26 & $3.43 \%$ \\
\hline 2009 & 157483.86 & 162117.90 & -4634.04 & $-1.27 \%$ \\
\hline 2010 & 195872.94 & 196653.10 & -780.16 & $-0.18 \%$ \\
\hline 2011 & 231854.91 & 233327.20 & -1472.29 & $-0.28 \%$ \\
\hline 2012 & 250792.26 & 255240.00 & -4447.74 & $-0.77 \%$ \\
\hline 2013 & 271246.86 & 282072.90 & -10826.04 & $-1.72 \%$ \\
\hline 2014 & 291387.70 & 302717.50 & -11329.80 & $-1.66 \%$ \\
\hline & & & & \\
\hline
\end{tabular}

\section{Conclusion}

Based on the AMSZ model, this paper makes a preliminary study on the dynamic efficiency of China's economy. The results show that before 2009, the dynamic efficiency of China's economy is characterized by large fluctuations. If you do not consider the indirect tax, then most of the time is dynamic invalid, consider the indirect tax, then most of the time is dynamic and effective. From 2009 onwards, both methods show that China's economy is in a dynamic invalid, and no longer large fluctuations, but the degree of dynamic inefficiency is not deep.

Over the past period, the high investment rate of China's economy does not mean excessive investment; on the contrary, accompanied by high economic growth rate in 2005-07 China's economy has very high net capital gains. However, after the financial crisis in 2008, China's economy has entered a new normal, and the economic structure is facing a transition. Even so, only 
slight dynamic inefficiencies are seen from the indicators of Net income/GDP. Therefore, we cannot simply from the high investment rate, savings rate to infer China's economic overinvestment. China as a developing country, the per capita capital stock is still very low, cannot ignore the role of investment in stimulating economic growth.

This paper argues that blind investment reduction will weaken China's international competitiveness, making China vulnerable to middle - income trap. Government to guide investment from the areas of excess capacity to new growth points, eliminate backward production capacity, to promote China's economic transformation and upgrading is a good solution.

\section{References}

[1] Phelps, E. S. The Golden Rule of Accumulation: A Fable for Growth man [J]. The American Economic Review, 1961, 51 (4):638-643.

[2] Diamond, Peter. Money in Search Equilibrium [J]. Econometric. 1984,1-20.

[3] Abel Andrew B, Mankiw N. Gregory, Summers Lawrence H and Zeck hauser Richard [J]. Assessing Dynamic Efficiency: Theory and Evidence [J]. Review of Economic Studies, 1989, 56: $1-20$.

[4] Feldstein, M. \& Summers, L. Is the Rate of Profit Falling? [J], Brooking Papers in Economic Activity, 1977a, 1977 (1): 211 -227

[5] Ibbotson, R. G. Stocks, Bonds, Bills, and Inflation, Market Results for 1926-1986, 1987 Yearbook. Chicago: R. G. Ibbotson Associates, Inc.

[6] Cohen Darrel S, Kennedy James E, Hasselt Kevin A. Are U.S. Investment and Capital Stocks at Optimal Levels[R]. FEDS Working Paper, 1995.

[7] Hahn, Jinso. Do Koreans Save Optimally [J] . Journal of Development Economics, 1955: 429422.

[8] Z. G. Yuan and Z. Song. Population Age Structure, Endowment Insurance System and Optimal Saving Rate [J]. Economic Research, 2000, 11.

[9] W. L. Huang and G .J. Sui. The Dynamic Efficiency of China's Economy - A Study Based on the Revision of the Golden Rule [J]. Journal of Shanxi Finance and Economics University, 2007.

[10] Y. D. Shi and Y. F. Qi. Dynamic Efficiency of China [J]. Global Economy, 2002, 8.

[11]Z. G. Yuan and Z .Y. He. Dynamic Efficiency of China since 1990s [J]. Economic Research, 2003. 